\title{
Effects of no-take area size and age of marine protected areas on fisheries yields: a meta-analytical approach
}

\author{
Frederic Vandeperre ${ }^{1}$, Ruth M. Higgins ${ }^{1}$, Julio Sánchez-Meca ${ }^{2}$, Francesc Maynou ${ }^{3}$, Raquel Goñi ${ }^{4}$, \\ Pablo Martín-Sosa ${ }^{5}$, Angel Pérez-Ruzafa ${ }^{6}$, Pedro Afonso ${ }^{1}$, Iacopo Bertocci ${ }^{7}$, Romain Crec'hriou ${ }^{8}$, Giovanni D’Anna ${ }^{9}$, \\ Mark Dimech $^{10}$, Carmelo Dorta ${ }^{11}$, Oscar Esparza ${ }^{6}$, Jesús M. Falcón ${ }^{511}$, Aitor Forcada ${ }^{12}$, Ivan Guala ${ }^{13}$, \\ Laurence Le Direach ${ }^{14}$, Concepción Marcos ${ }^{6}$, Celia Ojeda-Martínez ${ }^{12}$, Carlo Pipitone ${ }^{9}$, Patrick J. Schembri ${ }^{10}$, \\ Vanessa Stelzenmüller ${ }^{3}$, Ben Stobart ${ }^{4}$ \& Ricardo S. Santos ${ }^{1}$
}

\begin{abstract}
${ }^{1}$ Departamento de Oceanografia e Pescas, Universidade dos Açores, PT-9901-862 Horta, Portugal; ${ }^{2}$ The Meta-analysis Unit, Universidad de Murcia, Campus de Espinardo, 30100 Murcia, Spain; ${ }^{3}$ Institut de Ciències del Mar (CSIC). Psg. Marítim de la Barceloneta 37-49, 08003-Barcelona, Spain; ${ }^{4}$ Centro Oceanográfico de Baleares, Instituto Español de Oceanografía, Muelle Poniente s/n, Palma de Mallorca 07015, Spain; ${ }^{5}$ Centro Oceanográfico de Canarias, Instituto Español de Oceanografía, Avda. Tres de Mayo, 73, Edf. Sanahuja. 38005 Santa Cruz de Tenerife, Canary Islands; ${ }^{6}$ Deptartamento Ecología e Hidrología, Universidad de Murcia, Campus de Espinardo, 30100 Murcia, Spain; ${ }^{7}$ Dipartimento di Biologia, CoNISMa, University of Pisa, Via Derna 1, I-56126 Pisa, Italy; ${ }^{8}$ UMR 5244 CNRS-EPHE-UPVD, Biologie et Ecologie Tropicale et Méditerranéenne, Université de Perpignan Via Domitia, 52 Avenue Paul Alduy, 66860 Perpignan Cedex, France; ${ }^{9} \mathrm{CNR}-\mathrm{IAMC}$ Sede di Castellammare del Golfo, via Giovanni da Verrazzano 17, I-91014 Castellammare del Golfo, Italy; ${ }^{10}$ Department of Biology, University of Malta, Msida MSD2080, Malta; ${ }^{11}$ Grupo de Investigación BIOECOMAC, Dpto. de Biología Animal (Ciencias Marinas), Facultad de Biología, Universidad de la Laguna, c/ Francisco Sánchez s/n, 38206 La Laguna, Canary Islands; ${ }^{12}$ Unidad de Biología Marina, Departamento de Ciencias del Mar y Biología Aplicada, Universidad de Alicante. РОВ 99, E-03080 Alicante, Spain; ${ }^{13}$ Fondazione IMC, International Marine Centre, Onlus, Loc. Sa Mardini, 09072 Torregrande (Oristano), Italy; ${ }^{14}$ Groupement d'Intérêt Scientifique (GIS) Posidonie, Parc Scientifique et Technologique de Luminy, 13288 Marseille Cedex 9, France
\end{abstract}

\begin{abstract}
Marine protected areas (MPAs) are often promoted as tools for biodiversity conservation as well as for fisheries management. Despite increasing evidence of their usefulness, questions remain regarding the optimal design of MPAs, in particular concerning their function as fisheries management tools, for which empirical studies are still lacking. Using 28 data sets from seven MPAs in Southern Europe, we developed a meta-analytical approach to investigate the effects of protection on adjacent fisheries and asking how these effects are influenced by MPA size and age. Southern European MPAs showed clear effects on the surrounding fisheries, on the 'catch per unit effort' (CPUE) of target species, but especially on the CPUE of the marketable catch. These effects depended on the time of protection and on the size of the no-take area. CPUE of both target species and the marketable catch increased gradually by $2-4 \%$ per year over a long time period (at least 30 years). The influence of the size of the no-take area appeared to be more complex. The catch rates of the entire fishery in and around the MPA were higher when the no-take areas were smaller. Conversely, catch rates of selected fisheries that were expected to benefit most from protection increased when the no-take area was larger. Our results emphasize the importance of MPA size on its export functions and suggest that an adequate, often extended, time frame be used for the management and the evaluation of effectiveness of MPAs.
\end{abstract}

Correspondence:

Frederic Vandeperre, Departamento de Oceanografia e Pescas, Universidade dos Açores, PT-9901862, Horta, Portugal Tel.

+351292200400 Fax:

+ 351292200411 E-mail: vandeperre $a$ uac.pt

Current addresses: Vanessa Stelzenmüller: Johann Heinrich von Thünen Institute (vTI), Federal Research Institute for Rural Areas, Forestry and Fisheries, Institute of Sea Fisheries, Palmaille 9, 22767 
Keywords Catch per unit effort, fishery yields, marine protected area design, marine reserve, meta-analysis, spillover
Hamburg, Germany Iacopo Bertocci: CIIMAR, Centro Interdisciplinar de Investigação Marinha e Ambiental, Rua dos Bragas 289, 4050-123, Porto, Portugal

Received 20 Jan 2010 accepted 22 Nov 2010
Introduction

Material and methods

Case studies and data

Meta-analysis approach

Results

Meta-analysis

Simple meta-regressions

Multiple meta-regressions

Discussion

Acknowledgements

References

\section{Introduction}

Marine protected areas (MPA) are increasingly popular as management tools within the context of an ecosystem approach to fisheries management (Gell and Roberts 2003). They have the potential to sustain the fisheries adjacent to the protected areas while safeguarding species and habitats within. While much research effort has been invested in investigating the effects of protection on the conservation of habitats and species, less is known about the potential of MPAs to sustain fisheries (Hilborn et al. 2004; Sale et al. 2005). Within this context, this study attempts to fill the important need of empirical studies investigating the influence of MPA features such as no-take area size and age on its function as a fisheries management tool.

There are two main mechanisms through which MPAs can directly increase yields: (i) export of eggs and larvae from the MPA to the surrounding fished areas and (ii) spillover of juvenile and adult biomass across the MPA boundaries (Russ 2002; Gell and Roberts 2003; Sale et al. 2005). Spillover across MPA boundaries is the mechanism that has been most extensively investigated, partly because larval export is technically much more difficult to assess. Most evidence of MPA spillover effects comes from tropical systems (e.g. McClanahan and KaundaArara 1996; Russ and Alcala 1996, 1998; McClanahan and Mangi 2000; Kaunda-Arara and Rose 2004; Abesamis and Russ 2005; Floeter et al. 2006), whereas studies from the Mediterranean (Goñi et al. 2006, 2008; Stelzenmüller et al. 2007, 2008a,b, Stobart et al. 2009) and other temperate systems (Piet and Rijnsdorp 1998; Murawski et al. 2004, 2005; Jaworski et al. 2006) are more rare. Spillover has been investigated mainly for single MPAs through the observation of density gradients across reserve boundaries, the analysis of fisheries catch per unit effort/area (CPUE/CPUA) patterns and the examination of the size composition of fishery catches near reserves. The few studies that investigated effects of several temperate MPAs on surrounding fisheries (Murawski et al. 2004, 2005; Goñi et al. 2008; Stelzenmüller et al. 2008a) provided evidence of effort concentration and negative gradients of fisheries CPUE and CPUA with distance to the no-take area boundary. 
These previous studies have revealed that the direction and magnitude of MPA effects on fisheries can vary and are in fact difficult to predict (McClanahan and Mangi 2000; Sale et al. 2005). Although the number of studies investigating effects of MPAs is increasing, there is still a lack of empirical work evaluating the contribution of MPA design and age to the effects of MPAs, especially regarding effects on fisheries (Botsford et al. 2003; Hilborn et al. 2004; Sale et al. 2005). Most of our knowledge is based on modelling studies (De Martini 1993; Hastings and Botsford 1999, 2003; Nowlis and Roberts 1999; Rodwell et al. 2002, 2003; Botsford et al. 2003; Zeller and Reinert 2004), while only a few empirical studies attempted to tackle this issue. One of the difficulties lies in the way that MPAs have been designed. MPAs have often been created for conservation purposes and were designed on an opportunistic basis, resulting from political and economical compromises, rather than based on ecological criteria (Harmelin 2000). Moreover, a general framework for designing MPAs to allow their subsequent evaluation (e.g. through adaptive management) is lacking (Hilborn et al. 2004; Sale et al. 2005). Therefore, the few studies that did evaluate MPA features resulted from occasional changes in management plans (e.g. McClanahan and Mangi 2000). Another difficulty is the general scarcity of time series of spatially replicated monitoring data of appropriate resolution to allow for an evaluation of MPA effectiveness (Gell and Roberts 2003; Willis et al. 2003). Only recently have studies evaluated differences in MPA design and estimated recovery rates through multiple MPA comparisons. A common strategy has been to use certain types of meta-analysis, using published data (Mosqueira et al. 2000; Côté et al. 2001; Halpern and Warner 2002; Halpern 2003; Micheli et al. 2004; Molloy et al. 2009), raw empirical data (Russ et al. 2005; Claudet et al. 2008), or both (Guidetti and Sala 2007). These studies analysed biological variables such as fish density (Mosqueira et al. 2000; Côté et al. 2001; Halpern and Warner 2002; Halpern 2003; Micheli et al. 2004; Guidetti and Sala 2007; Claudet et al. 2008; Molloy et al. 2009), fish biomass (Halpern and Warner 2002; Halpern 2003; Micheli et al. 2004; Russ et al. 2005; Guidetti and Sala 2007), fish size (Halpern and Warner 2002; Halpern 2003) and fish diversity measures (Côté et al. 2001; Halpern and Warner 2002; Halpern 2003; Claudet et al. 2008), comparing locations inside and outside MPAs, and offered important insights into the mechanisms by which MPAs may contribute to the protection and restoration of biomass and biodiversity. However, to our knowledge, no multiple comparative studies have attempted to investigate the influence of MPA features, such as age and no-take area size, on the export functions of MPAs, in spite of many authors arguing for the need for such studies (Roberts et al. 2001; Hilborn et al. 2004; Sale et al. 2005). The results of these meta-analytical studies were often inconsistent and somewhat contradictory: no age effect (Mosqueira et al. 2000; Côté et al. 2001) vs. slow (Russ et al. 2005; Guidetti and Sala 2007; Claudet et al. 2008; Molloy et al. 2009) vs. fast recovery (Halpern and Warner 2002) and no effect (Côté et al. 2001; Halpern 2003; Guidetti and Sala 2007 ) vs. positive effect of no-take area size (Claudet et al. 2008), leading us to expect similarly variable results for fisheries data.

The aim of the present study was to evaluate the effects of MPAs on catches of the surrounding fisheries, and the extent to which these vary with the following MPA features: time of protection, size of the no-take area and distance from the no-take area border. Therefore, we collected catch and effort data from in and around 13 MPAs located in the Mediterranean and NE Atlantic region. These regions are characterized by a largely artisanal, multispecies fishery, which in the Mediterranean accounts for $80 \%$ of the EU fishing fleet and generates more than 100000 jobs (COM 2002). These artisanal fisheries are typified by highly diverse fishing gears and target species, as well as a marked seasonality. While they may have specific target species, they also may tend to optimize the aggregated catch (Goñi et al. 2008). For artisanal fisheries in particular, which are showing signs of decline in many coastal areas (Gomez et al. 2006), MPAs may be the most opportune management tool (Hilborn et al. 2004). We developed a meta-analytical approach to (i) analyse trends in CPUE data gathered in and around Atlanto-Mediterranean MPAs and (ii) to relate these trends to important MPA features. The advantage of using raw empirical data from a single biogeographical region is that it allows us to avoid problems resulting from publication bias as well as those associated with analysing results from different biogeographical regions (Claudet et al. 2008). We performed the analysis on four different response variables, differentiating between CPUE of a single gear (1) (targeting a particular species/group) and standard- 
ized gears (S) (combining CPUEs from all the gears that intentionally or unintentionally catch those species/groups) and between CPUE of target species (T) and the marketable catch (M), assuming different responses to protection. We calculated the response variables for standardized gears to enable generalizations on the effects of MPAs on an entire fishery for a given species/group. In contrast, in the case of the analysis for single gears, we investigated the effects of MPAs for fisheries that specifically target that species/group and that are expected to benefit most from protection.

\section{Material and methods}

\section{Case studies and data}

To investigate the effects of protection on commercial catches in and around MPAs in the western Mediterranean and eastern Atlantic region, we collected raw catch and landings data from the commercial fisheries from 13 MPAs and yielded 80 data sets, each data set representing catch or landings data for 1 year for a specific MPA. The data were derived from existing databases that were compiled from a variety of national and international programmes and research projects in which the co-authors participated. The data were subsequently filtered using the following criteria: (i) reliable and detailed spatially referenced catch and effort data, (ii) presence of adequate reference areas and (iii) comparable protection status (for instance the presence of a no-take area and the level of enforcement), resulting in a reduced data set of 28 case studies, from 7 MPAs (Fig. 1, Table 1), with a time range of 0 to 30 years of protection.

The MPAs that were retained for analysis were Carry-le-Rouet, Cerbère-Banyuls, Medes Islands, Cabo de Palos, Columbretes Islands, La Graciosa and La Restinga (Fig. 1, Table 1) (Planes et al. 2008, Vandeperre et al. 2008). They are located in coastal zones, near offshore and oceanic islands and represent littoral habitats such as rocky reefs, mud, gravel and sand bottoms, and Posidonia oceanica and Cymodocea nodosa seagrass meadows that are typical for the respective regions (Table 1). All MPAs differed in their spatial designs, size and year of establishment (Table 1). The MPAs, with the exception of Carry-le-Rouet, typically consist of a no-take area, where fishing is prohibited, and a partial-take area, where only some artisanal fishing and sometimes recreational fishing is allowed. Fishing within the partial-take area is limited to authorized vessels and to the use of certain fishing gears. In the waters adjacent to Carry-le-Rouet, which only consists of a no-take area, the fisheries are also largely traditional. The size of the different areas varies among MPAs, ranging from 65 to 1800 ha for the no-take areas and from 0 to 68775 ha for the partial-take areas (Table 1). The artisanal fisheries operating inside the partial-take areas use a variety of fishing gears such as seine nets, gillnets, trammel nets, longlines, traps and hand lines, targeting many different species depend-
Figure 1 Map of the study area and the location of the MPAs included in the study: 1. Carry-le-Rouet,

2. Banyuls-Cerbére, 3. Medes Island,

4. Columbretes Islands, 5. Cabo de

Palos, 6. La Graciosa and

7. La Restinga.

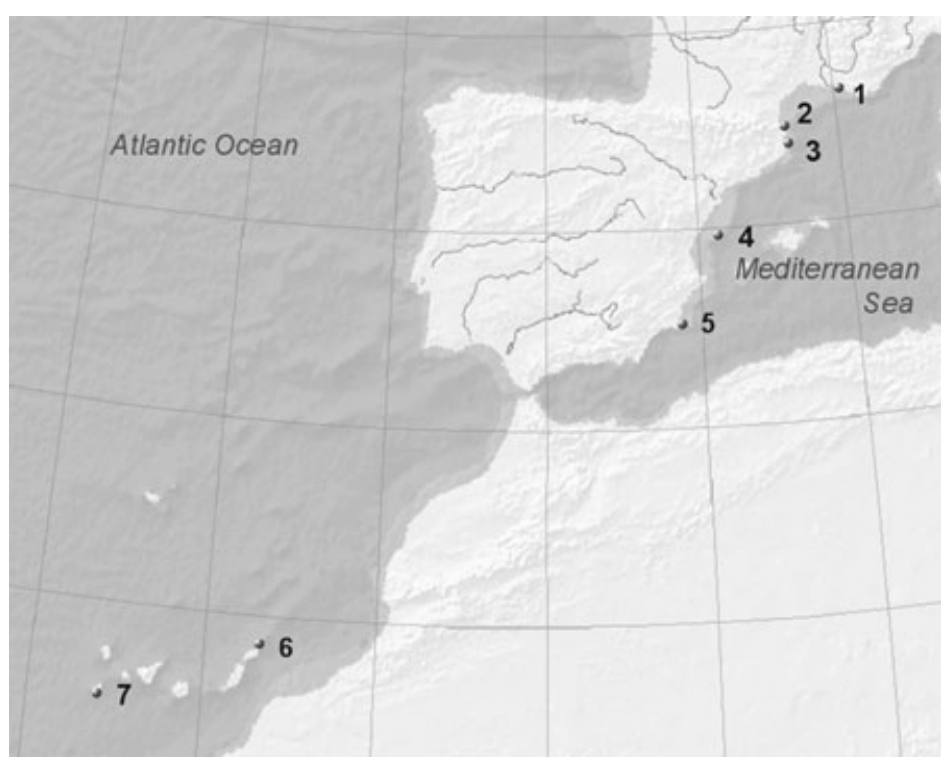



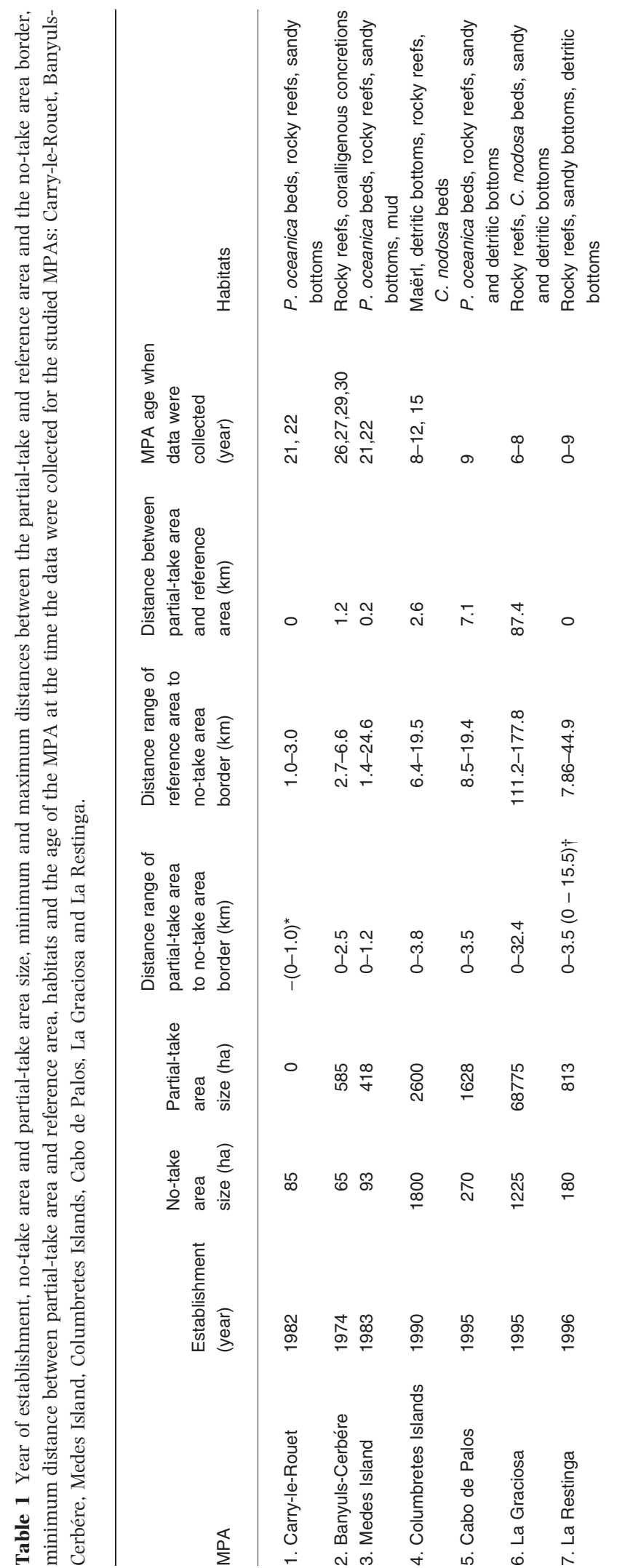

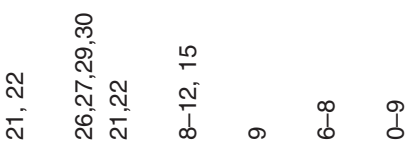

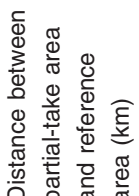

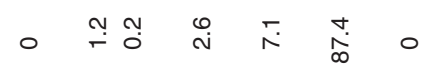

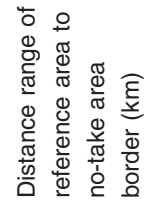

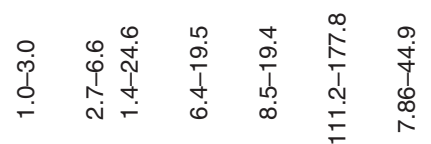

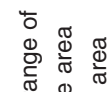

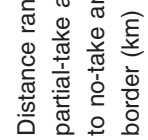

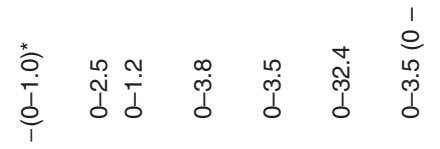

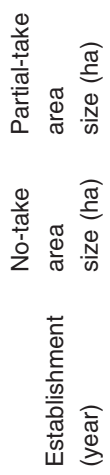

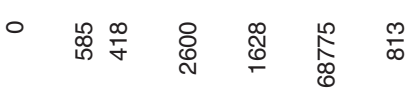

œ

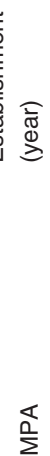

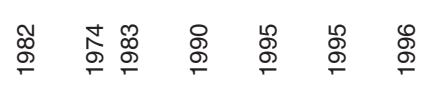

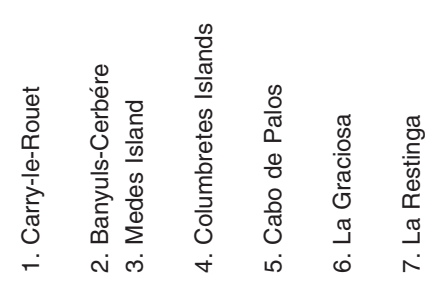

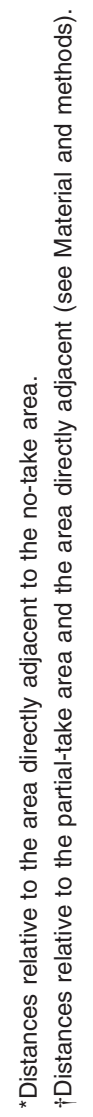


ing on the season. Close examination of Table 1 reveals some gaps in our data set, i.e. a shortage of case studies with intermediate characteristics, such as MPAs with intermediate sizes and studies conducted between 15-22 and 22-26 years after MPA establishment, and a trend for more recent MPAs to be larger. This is especially so for the partial-take areas where some fishing is still allowed. These limitations need to be considered for the analyses and their interpretation.

A major problem in measuring effects of protection by MPAs is the lack of independent control sites (Gell and Roberts 2003; Halpern et al. 2004; Samoilys et al. 2007). To overcome this, we adopted a comparative approach. CPUE data of the area directly adjacent to the no-take area of the MPA were compared to data from a comparable area far from the MPA, i.e. an area with similar habitat characteristics (Russ et al. 2005) and subjected to similar fishing practises where no or limited influence of the MPA is expected. This reference area cannot be considered a control site sensu strictu, mainly because the extent of the influence of MPAs and the factors determining this extent are complex and often unknown (Gell and Roberts 2003; Halpern et al. 2004). We chose the reference areas with particular care on a case-by-case basis and only those MPAs where an acceptable reference location could be designated were retained for analysis. The area directly adjacent to the no-take area coincided with the partial-take area or, in the case of Carry-leRouet, with the area directly outside the MPA. In the case of La Restinga, the fishing tactics and the boats operating in the partial-take area and the immediate vicinity of the MPA are the same, even though different regulations are in place. As the landings in these two areas were not recorded separately, we considered the two zones as one entity for the analysis.

We developed a generic approach using different response variables as artisanal fisheries in this study were very diverse in relation to their tactics and target species. We considered four different response variables: (T1) CPUE of target species for a single gear, (M1) CPUE of the marketable catch for a single gear, (TS) CPUE of target species for standardized gears and (MS) CPUE of the marketable catch for standardized gears. The marketable catch (M1 and MS) was the aggregated catch of all target and commercialized by-catch species, i.e. species with commercial value that are not specifically targeted by the gear. For response variables relating to a single gear, T1 and M1, we selected for each MPA the gear targeting a particular species/group that was expected to benefit most from protection (Table 2). All CPUE values were calculated with the best possible precision depending on the data:

$$
\begin{aligned}
\text { CPUE } & =\text { Weight }(\mathrm{kg}) /[\text { Time }(\text { days or hours }) \\
& \times \text { Length of net }(\mathrm{km}) \times \text { Number of hooks }]
\end{aligned}
$$

Although the units of CPUE varied between gears, these differences become irrelevant following standardization of data and the fact that meta-analysis is based on unit-free ratios. The aim of standardization (response variables TS and MS) was to enable a joint assessment of trends in CPUE for different gears and to enable a generalization of the effects of MPAs for an entire fishery. We used generalized linear models (GLMs) with a Gaussian distribution and a log link function to standardize the catch data for each MPA separately (Maunder and Punt 2004). The main GLM factors besides 'gear' were 'month' and 'year'. For the analysis, we included only CPUE data from gear types that were used in both the

\begin{tabular}{|c|c|c|}
\hline MPA & Gear & Main target species \\
\hline Carry-le-Rouet & Trammel net & $\begin{array}{l}\text { Red scorpionfish (Scorpaena scrofa, Scorpaenidae), goatfishes (Mullus spp., } \\
\text { Mullidae), porgies (Sparidae) }\end{array}$ \\
\hline Banyuls-Cerbére & Gill net & $\begin{array}{l}\text { Axillary seabream (Pagellus acarne, Sparidae),common pandora (Pagellus erythrinus, } \\
\text { Sparidae), European hake (Merluccius merluccius, Merluccidae) }\end{array}$ \\
\hline Medes Island & Gill net & Common pandora \\
\hline Columbretes Islands & Trammel net & European spiny lobster (Palinurus elephas, Palinuridae) \\
\hline Cabo de Palos & Trammel net & $\begin{array}{l}\text { Red scorpionfish, common dentex (Dentex dentex, Sparidae), brown meager } \\
\text { (Sciaena umbra, Sciaenidae) }\end{array}$ \\
\hline La Graciosa & Hook and line & Red porgy (Pagrus pagrus, Sparidae) \\
\hline La Restinga & Snorkeling handline & Parrotfish (Sparisoma cretense, Scaridae) \\
\hline
\end{tabular}

Table 2 Gear and main target species used in the single gear analysis (T1 and M1) for each MPA. 
areas surrounding the no-take area and the reference area. The gear types included different types of gillnets, trammel nets, bottom longlines and hand lines targeting fishes of the families Sparidae, Scorpaenidae, Mullidae, Lophiidae, Serranidae, Scaridae, Berycidae, Polymixiidae and Balistidae as well as Palinurid lobsters. Further, we excluded from the analyses catch data of highly migratory species and catches of fishing gears targeting these species as possible MPA benefits for these species are unlikely to be detected by our methodology (see Le Quesne and Codling 2009). Because not all response variables could be calculated for each data set, the different analyses were conducted on a subset of MPAs (5-6) and case studies (20-26) (see Tables 3, 4 and 5).

\section{Meta-analysis approach}

We developed a meta-analytical approach to relate differences in CPUEs between fishing grounds adjacent to no-take areas and at reference sites with MPA features (time since protection, size of the no-take area and distance from the no-take area border). We used log-response ratios (L), a unit-free measure, comparing the mean CPUE adjacent to the no-take area and at the reference site (Hedges et al. 1999):

$$
L_{i}=\log _{e}\left(\frac{\bar{X}_{i, A}}{\bar{X}_{i, F}}\right)
$$

and calculated the corresponding within-study variances $v_{L, i}$ as follows (Hedges et al. 1999):

$$
v_{L, i}=\frac{s_{i, A}^{2}}{n_{i, A} \bar{X}_{i, A}^{2}}+\frac{s_{i, F}^{2}}{n_{i, F} \bar{X}_{i, F}^{2}}
$$

where $L_{i}$ is the log-response ratio for case study $i$, $\bar{X}_{i, A}$ and $\bar{X}_{i, F}$ are the mean CPUEs adjacent to the no-take area (A) and at the reference site (F), $s_{i, A}^{2}$ and $s_{i, F}^{2}$ are the variances associated with $\bar{X}_{i, A}$ and $\bar{X}_{i, F}, n$ is the sample size, i.e. the number of hauls (or fishing sets sampled). We included zero values for the calculation of mean CPUE of target species, while no zero catches were registered for the marketable catch. Positive values of these log-response ratios indicate higher CPUE values adjacent to than far from the MPA. For every case study, the distance to the notake area border was calculated as the mean distance to the border of each haul or each trip inside the adjacent area or of the mean distance to the border of the area itself, depending on the available data.

Weighted average effect sizes were computed using random effects meta-analysis, assuming that the effect estimates for each case study measured different parametric effects inherent to the different designs and characteristics of the MPAs. Therefore, the analysis explicitly takes both the within-study and between-study variances into account for the weighting (Gurevitch and Hedges 1999; Hedges et al. 1999):

$$
w_{i}=\frac{1}{v_{L, i}+v_{b}}
$$

where $w_{i}$ is the weight of case study i, $V_{L, i}$ is the within-study variance of case study $\mathrm{i}$ and $v_{b}$ is the between-study variance.

Association between effect sizes and moderator variables, i.e. the MPA features, was first analysed using weighted simple mixed-effects regression models (by restricted maximum likelihood) (Rosenberg et al. 2000). In a second step, we constructed three weighted multiple mixed-effects regression models (by unrestricted maximum likelihood) for each response variable i.e. the three possible combinations of two moderator variables: model A Time since protection $\times$ Distance from no-take area,

\begin{tabular}{|c|c|c|c|c|c|c|c|c|}
\hline \multirow[b]{2}{*}{$\begin{array}{l}\text { Response } \\
\text { variable }\end{array}$} & \multirow[b]{2}{*}{$n$} & \multirow[b]{2}{*}{$\begin{array}{l}\text { Mean } \\
\text { Effect Size }\end{array}$} & \multicolumn{2}{|c|}{$\begin{array}{l}95 \% \text { Confidence } \\
\text { Intervals }\end{array}$} & \multirow[b]{2}{*}{$P$-Value } & \multirow[b]{2}{*}{ Q-Value } & \multirow[b]{2}{*}{$\mathrm{df}(\mathrm{Q})$} & \multirow[b]{2}{*}{$P$-Value } \\
\hline & & & $\begin{array}{l}\text { Lower } \\
\text { limit }\end{array}$ & $\begin{array}{l}\text { Upper } \\
\text { limit }\end{array}$ & & & & \\
\hline $\mathrm{T} 1$ & 26 & -0.481 & -0.623 & -0.340 & $<0.001$ & 737.589 & 25 & $<0.001$ \\
\hline M1 & 21 & -0.334 & -0.493 & -0.175 & $<0.001$ & 544.327 & 20 & $<0.001$ \\
\hline TS & 20 & -0.538 & -0.628 & -0.448 & $<0.001$ & 273.527 & 19 & $<0.001$ \\
\hline MS & 22 & -0.378 & -0.487 & -0.269 & $<0.001$ & 410.294 & 21 & $<0.001$ \\
\hline
\end{tabular}
model B - Time since protection $\times$ Size of the no-take area and model $\mathrm{C}$ - Distance from no-take
Table 3 Summary of the random effects meta-analysis for each of the four response variables (T1, M1, TS and MS).

$n$ is the number of case studies in each analysis. 
MPA size and age: effects on fisheries $F$ Vandeperre et al.

Table 4 Summary of the weighted simple mixed-effects regression models for each of the four response variables (T1. M1. TS and MS).

Table 5 Summary of the weighted multiple mixed-effects regression models for each of the four response variables (TS, T1, MS and M1): model A - Time since protection $\times$ Distance from no-take area, model B - Time since protection $\times$ Size of the no-take area and model C - Distance from no-take area $\times$ Size of the no-take area; $n$ is the number of case studies in each analysis.

\begin{tabular}{lllllll}
\hline $\begin{array}{l}\text { Response } \\
\text { variable }\end{array}$ & $n^{\circ}$ MPAs & $n$ & $\begin{array}{l}\text { Moderator } \\
\text { variable }\end{array}$ & Slope & $P$ & $r^{2}$ \\
\hline T1 & 6 & 26 & Time protected (year) & 0.01427 & 0.16243 & 0.07 \\
T1 & 6 & 26 & $\log ($ Distance+1) (km) & 0.00323 & 0.98621 & 0.00 \\
T1 & 6 & 26 & Log (Size) (ha) & 0.21731 & 0.12363 & 0.07 \\
M1 & 6 & 21 & Time protected (year) & $0.02997^{*}$ & 0.00354 & 0.30 \\
M1 & 6 & 21 & Log (Distance+1) (km) & -0.42729 & 0.14014 & 0.00 \\
M1 & 6 & 21 & Log (Size) (ha) & $0.48872^{*}$ & 0.00100 & 0.25 \\
TS & 5 & 20 & Time protected (year) & $0.02078^{*}$ & 0.01374 & 0.22 \\
TS & 5 & 20 & Log (Distance+1) (km) & $-0.76308^{*}$ & 0.00001 & 0.48 \\
TS & 5 & 20 & Log (Size) (ha) & $-0.36823^{*}$ & 0.00067 & 0.31 \\
MS & 6 & 22 & Time protected (year) & $0.02815^{*}$ & 0.00005 & 0.44 \\
MS & 6 & 22 & Log (Distance+1) (km) & $-0.90196^{*}$ & 0.00001 & 0.45 \\
MS & 6 & 22 & Log (Size) (ha) & $-0.55584^{*}$ & 0.00001 & 0.42 \\
& & & & & \\
\hline
\end{tabular}

$n$ is the number of case studies in each analysis.

*Indicates significant regressions at $\alpha=0.05$.

\begin{tabular}{|c|c|c|c|c|c|c|c|c|}
\hline $\begin{array}{l}\text { Response } \\
\text { variable }\end{array}$ & $\mathrm{n}^{\circ}$ MPAs & $n$ & model & $\begin{array}{l}\text { Slope time } \\
\text { protected } \\
\text { (year) }\end{array}$ & $\begin{array}{l}\text { Slope } \\
\text { log (Dist.) } \\
(\mathrm{km})\end{array}$ & $\begin{array}{l}\text { Slope } \\
\text { log (Size) } \\
\text { (ha) }\end{array}$ & $P$ (model) & $r^{2}$ \\
\hline $\mathrm{T} 1$ & 6 & 26 & A & $0.0214^{*}$ & 0.1977 & & 0.2277 & 0.1 \\
\hline $\mathrm{T} 1$ & 6 & 26 & B & 0.0183 & & $0.4085 \dagger$ & 0.0006 & 0.3 \\
\hline T1 & 6 & 26 & C & & 0.0574 & $0.3318 \dagger$ & 0.0401 & 0.15 \\
\hline M1 & 6 & 21 & A & $0.0363 \dagger$ & 0.1588 & & 0.0140 & 0.31 \\
\hline M1 & 6 & 21 & B & $0.0373 \dagger$ & & $0.6412 \dagger$ & $<0.0001$ & 0.69 \\
\hline M1 & 6 & 21 & $\mathrm{C}$ & & $-0.9063 \uparrow$ & $1.047 \dagger$ & $<0.0001$ & 0.75 \\
\hline TS & 5 & 20 & A & -0.0063 & $-0.5918 \dagger$ & & $<0.0001$ & 0.51 \\
\hline TS & 5 & 20 & B & $0.0157 \dagger$ & & $-0.3509 \dagger$ & 0.0004 & 0.43 \\
\hline TS & 5 & 20 & $C$ & & $-0.4307 \dagger$ & -0.1322 & $<0.0001$ & 0.52 \\
\hline MS & 6 & 22 & A & -0.0002 & $-0.4732 \dagger$ & & 0.0013 & 0.41 \\
\hline MS & 6 & 22 & B & 0.0072 & & $-0.3574 \dagger$ & 0.0004 & 0.44 \\
\hline MS & 6 & 22 & $C$ & & $-0.2898^{\star}$ & $-0.2398^{\star}$ & 0.0001 & 0.49 \\
\hline
\end{tabular}

${ }^{*}$ Indicates significant regressions at $\alpha=0.10$.

$\dagger$ Indicates significant regressions at $\alpha=0.05$. area $\times$ Size of the no-take area (Rosenberg et al. 2000). The number of studies (n) did not allow constructing models with all three moderator variables. We tested for linear correlation between moderator variables to account for collinearity.

Analyses were carried out using the following software packages: R, Comprehensive Meta-analysis 2, SPSS 15.0 (meta-analysis macro metareg.sps, developed by D.B. Wilson) and Statistica 6.0.

\section{Results}

\section{Meta-analysis}

Mean effect sizes were negative for all analyses, implying that the CPUEs from the area adjacent to the no-take area were lower than in the reference locations (Table 3). Yet, effect sizes for all response variables were heterogeneous (Q statistics, Table 3), suggesting that the influence on CPUEs varied among MPAs. The mean effect sizes were lower for the catches of target species (TS and T1), compared to the marketable catch (MS and M1). The mean effect size for TS and MS were lower than T1 and M1, respectively (Table 3).

\section{Simple meta-regressions}

Simple meta-regressions revealed a positive relationship between effect size and time of protection for all four response variables, which was significant for three out of four response variables (TS, MS and 

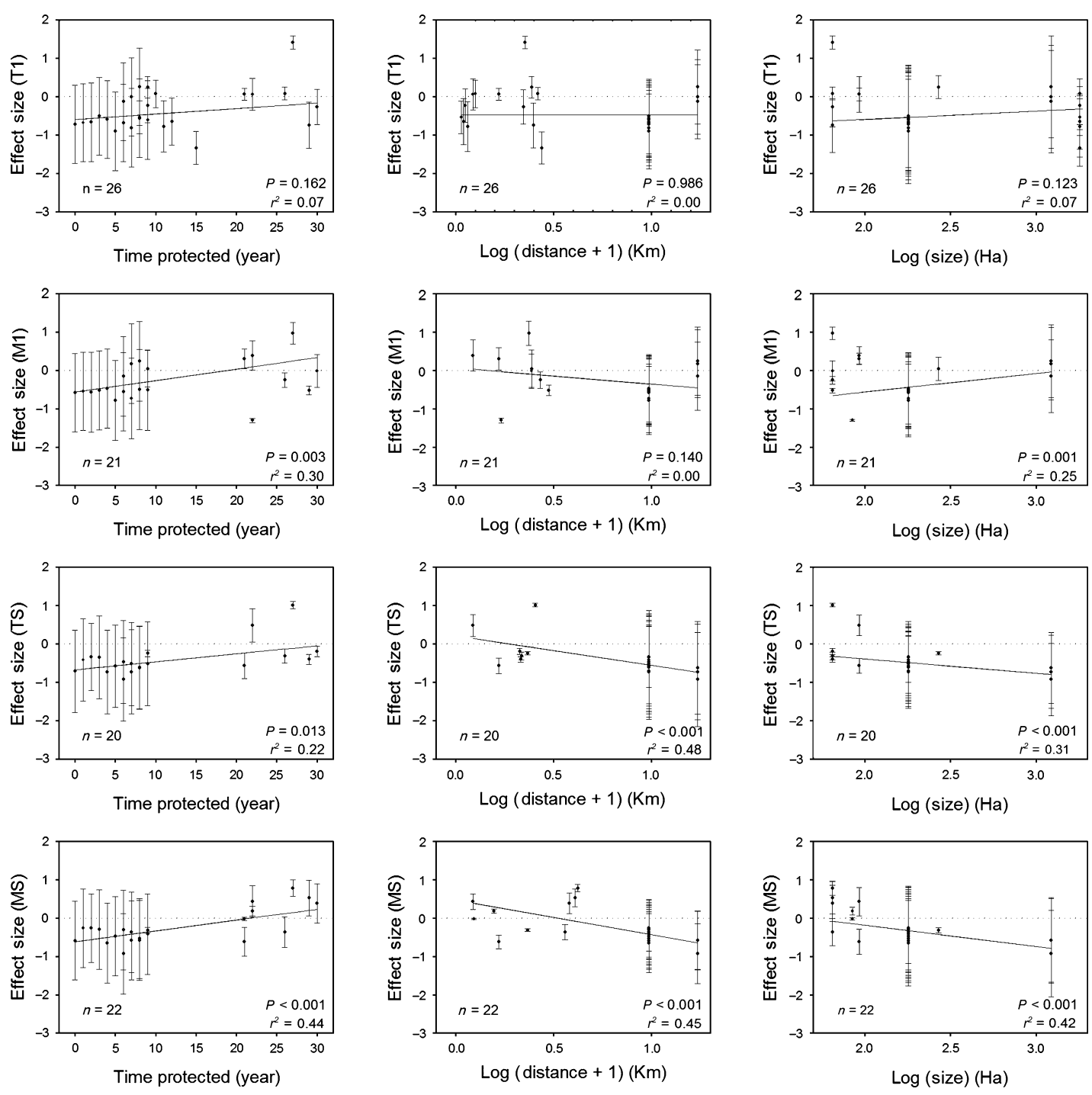

Figure 2 Plots of the weighted simple mixed-effects regression models of effect sizes versus time protected, distance from the no-take area boundary and size of the no-take area for each of the four response variables (TS, T1, MS and M1). Vertical bars represent the weight of each case study in the analysis.

M1) (Fig. 2, Table 4). For the significant regressions, $r^{2}$ values ranged between 0.22 and 0.44 . The plots showed that the difference between effect sizes increased with time (Fig. 2) and suggested higher heterogeneity in response to protection with time. Moreover, results of linear regressions, i.e. the intercept and the slopes, indicated a stronger effect of time for MS and M1. Regression lines indicated that CPUEs of marketable catch, for both the entire fishery and individual gears (MS and M1), became comparable to those from reference areas after approximately 20 years (22 and 19 respectively) as effect sizes reached zero. The regression lines for the effect sizes TS and T1, the CPUE of target species for standardized gears and single gears, never reached 0 within the range of the study period (Fig. 2).

The relationship between effect size and distance to the no-take area was generally negative, indicating that effect sizes were generally lower further from the no-take area boundary (Table 4). This relationship was significant for TS and MS. $r^{2}$ values for these two response variables were very similar, namely 0.45 and 0.48 .

Simple meta-regressions of effect sizes vs. size of the no-take area showed significantly negative slopes when analysing the catches of standardized 
gears, TS and MS, with improved CPUE manifesting across the fishery for smaller no-take areas. Results contrasted for single gears where positive slopes were observed, which were only significant for M1. $r^{2}$ values for the significant regressions ranged from 0.25 to 0.42 .

\section{Multiple meta-regressions}

Correlation analysis detected some collinearity between the moderator variables, but patterns were weak and were not deemed to have much influence on our analyses, as shown by the results. In general, none of the regression models (A, B and $\mathrm{C}-$ see Table 5) alone appeared to explain fully the variability of the response variables. All models except one, i.e. model A for response variable $\mathrm{T} 1$, were significant, even if the $r^{2}$ values of the significant models vary considerably (Table 5).

Multiple regression models for single gears (M1 and T1) exhibited similar trends, i.e. a positive effect of time since protection and of size of the no-take area, but the trends for M1 appear to be stronger (Table 5). Slopes were generally steeper, and the models explained a larger proportion of the variability. Models A $\left(P=0.014, r^{2}=0.30\right)$ and $\mathrm{B}$ $\left(P<0.001, r^{2}=0.69\right)$ indicated a strong positive relation between M1 and time since protection, while model $\mathrm{B}$ also exhibited a strong positive relationship between $\mathrm{M} 1$ and size of the no-take area. Model C $\left(P<0.001, r^{2}=0.75\right)$ evidenced a negative relationship with distance from the no-take area boundary and a positive relationship with size of the no-take area. The analyses suggested a CPUE increase for M1 of 4\% for each year of protection and a $90 \%$ to $185 \%$ increase for each increment of 10 ha of the no-take area. The CPUE of M1 decreased by $6 \%$ for each $\mathrm{km}$ of mean distance further away from the no-take area boundary. For response variable $\mathrm{T} 1$, for which no relationships with the moderator variables were discovered with simple linear regressions, the multiple regression models $\mathrm{B}$ and $\mathrm{C}$ were significant, but the $r^{2}$ values were low (model B: $P<0.001, r^{2}=0.30$; model C: $P=0.04, r^{2}=0.15$ ) (Table 5). Model B revealed a positive relationship for time since protection and size of the no-take area. Model $\mathrm{C}$ showed a positive relationship with the size of the no-take area. CPUE values for $\mathrm{T} 1$ increased by $2 \%$ per year and between $39 \%$ and $50 \%$ for each additional 10 ha of no-take area.
The results of the multiple regression models for TS and MS exhibited similar relationships, i.e. a negative relationship with both the size of the notake area and the distance from the no-take area boundary (Table 5). The three models for response variable TS suggested that moderator variable distance from the no-take area was the most important in explaining variability (Table 5). In fact, in both models in which this variable appeared (models A and C), distance from the no-take area was the only significant moderator variable. The slopes of models A and C indicate a CPUE decrease between $3.5 \%$ and $4.5 \%$ for each $\mathrm{km}$ of mean distance away from the no-take area border within our data range $(0.23-16.21 \mathrm{~km}) . r^{2}$ of the two models were very similar and only slightly higher than the simple regression model for distance to the no-take area boundary: 0.52 and 0.51 when compared with 0.48. Model B showed a positive effect of time since protection and a negative effect of the size of the no-take area $(P<0.001$, $\left.r^{2}=0.43\right)$. The slopes indicated a $2 \%$ increase of CPUE per year of protection and a 30\% decrease for each additional 10 ha of no-take area within the analysed range (65-1225 ha). For MS, model A $\left(P=0.001, r^{2}=0.41\right)$ showed a strongly negative relationship for distance from the no-take area, while there was no significant relationship with time since protection. Model B $(P<0.001$, $\left.r^{2}=0.44\right)$ showed a negative relationship with the size of the no-take area and no relationship with time since protection. Model C $(P<0.001$, $\left.r^{2}=0.49\right)$ showed a non-significant $(P<0.1)$ negative relationship of both distance from the no-take area boundary and size of no-take area, but explained a higher fraction of the variability than models A and B. Model results indicated a CPUE decrease for MS between 2.5\% and 3.8\% for each $\mathrm{km}$ of mean distance further away from the no-take area boundary and between $21 \%$ and $30 \%$ for each expansion of 10 ha of the no-take area.

For all four response variables, we found indications of an effect of protection through the presence of significant negative CPUE gradients away from the no-take area boundary (MS), through the presence of a significant positive effect of time on the CPUE (T1) or both (TS and M1). Furthermore, the direction of the relationship with the size of the no-take area differed between CPUEs for a single gear (T1 and M1) and CPUEs of standardized gears (TS and MS). 


\section{Discussion}

This study aimed at assessing the influence of MPA features such as no-take area size and age on its function as a fisheries management tool with the help of a meta-analytical approach using empirical data. It has been recognized that the interpretation of effects of MPAs on the surrounding fisheries is particularly delicate owing to many confounding factors that can lead to misinterpretation (Gell and Roberts 2003; Murawski et al. 2004). These confounding factors are basically related to issues of replication and adequacy of controls (Willis et al. 2003; Murawski et al. 2004). In the present study, interpretation was mainly complicated by habitat differences between locations and between MPAs, presence of environmental gradients and spatial heterogeneity of the data (for a discussion see Murawski et al. 2004). Therefore, special attention was given to the design of the study and the selection of reference locations. As demonstrated by Russ et al. (2005), carefully designed spatial comparisons are useful and allow meaningful inferences to be drawn.

When analysing patterns in CPUE, an important confounding effect is the spatial heterogeneity of effort (Murawski et al. 2004). The implementation of an MPA generates a redistribution of fishing effort through the displacement of fishing activity from the closed area to the surrounding areas still open to fishing (Halpern et al. 2004). Both modelling and empirical studies have supported the hypothesis that this redistribution is often associated with a concentration of effort around the MPA boundaries (McClanahan and Kaunda-Arara 1996; Murawski et al. 2005; Goñi et al. 2006, 2008; Kellner et al. 2007; Stelzenmüller et al. 2008a). This concentration is because of higher catch rates, larger sizes of target species or the expectation of increased benefits because of the presence of an MPA (Murawski et al. 2004). Mean CPUE values in the present analysis were calculated from commercial fisheries data. Unlike scientific surveys, the commercial operations were not randomly distributed in space. The number of catches from an area was thus proportional to the effort invested in that same area (Stelzenmüller et al. 2008a). Moreover, when the effort is unequally distributed, density is reflected by catch per unit area (CPUA) rather than by CPUE (for a discussion, see Goñi et al. 2006). Using CPUE as a density index would theoretically lead to an under- estimation of density at locations with high effort concentration. Therefore, the results reflect the yields experienced by the fishermen, but the effort concentration may obscure MPA effects (McClanahan and Kaunda-Arara 1996; Halpern et al. 2004). Stelzenmüller et al. (2008a) and Goñi et al. (2006, 2008) identified such concentration around four of the seven MPAs included in this study and suggested that these patterns generally apply to coastal MPAs where artisanal fishing fleets operate in the surrounding waters. This may explain the negative values we obtained for effect sizes shortly after MPA establishment and the mean effect sizes of all four response variables, and why our analysis revealed a small MPA effect on the CPUE of target species for a single gear, although we expected these yields to be impacted most by the MPAs. Furthermore, our results indicate that, despite the high concentration of effort, a general decline in catch rate occurred with increasing mean distance from the no-take area, although not always significant. Three response variables declined between $25 \%$ and $60 \%$ for each 10-km distance interval away from the no-take area. This CPUE gradient was stronger for the effect sizes of standardized gears (between 35\% and $60 \%$ decrease in CPUE per 10-km interval), for which we expect an equal or smaller concentration effect compared to the single gear analyses. Acknowledging that in the present study the distance from the no-take area boundary was not directly interpretable as a result of the methodology, the results obtained are in accordance with more robust studies for single MPAs that take into account other factors such as depth. For Columbretes Islands Marine Reserve, Goñi et al. (2006) demonstrated that CPUE declined with distance from the no-take area boundary, with a depression of CPUE at the boundaries followed by a plateau caused by local depletion associated with a concentration of fishing effort. Such depressed densities at no-take area boundaries, related with increased effort, were also predicted and evidenced by Kellner et al. (2007). Murawski et al. (2004, 2005) showed a decrease in densities of target species within the first $10 \mathrm{~km}$ from the boundaries of temperate closed areas off New England, with an increased CPUE within the first $4 \mathrm{~km}$. Kaunda-Arara and Rose (2004) identified CPUE gradients of target species outside two tropical no-take areas in Kenya. While these studies investigated patterns for single species or single fisheries, our analysis suggest that these 
patterns are also detectable at the scale of the entire fishery around an MPA.

The primary objective of this study was to investigate different MPA features and to gain a deeper insight into the effects of MPAs on adjacent fisheries through the comparison of different response variables. The results revealed a gradual increase of the CPUE of $2-4 \%$ per year for the period of the study (30 years). Scarcity of data between 10 and 20 years of protection precludes the precise estimation of recovery rates and the investigation into more complex, i.e. nonlinear, relationships. Nonetheless, spatial comparisons can provide rapid and approximate inferences about recovery rates (Russ et al. 2005), notwithstanding that the recovery process is complex and influenced by a wide range of factors (Jennings 2001). Previous studies showed variable and in some cases contrasting trends in recovery rates of biomass inside no-take areas, although the hypothesis that recovery persists over long time periods (i.e. decades) seems to be gaining weight (for discussions, see Russ and Alcala 2004; Russ et al. 2005; Claudet et al. 2008; Molloy et al. 2009). Our results are in line with this hypothesis as they suggest that effects of MPAs on catch rates outside no-take areas develop over long time periods and continue at least until 30 years of protection. This is critically important for management as well as for the interpretation of MPA effectiveness, which should both be thought of within this temporal perspective. Our findings, however, should be interpreted with care. The effects of time and distance from the no-take area on CPUE ratios are an indication of spillover, but are likely influenced by other factors such as the evolution of total effort and effort fluctuations near the no-take area boundary (Kellner et al. 2007). Nonetheless, the combined effect of time and distance from the no-take area we observed is supported by observations from Columbretes Islands Marine Reserve (Stobart et al. 2009). After 8 years of protection, multispecies fish CPUEs were lower near the reserve boundary $(0-0.5 \mathrm{~km})$ than further away $(0.5-5 \mathrm{~km}$, or $>5 \mathrm{~km})$, and this CPUE increased over time (up to year 16) almost approaching the values of CPUE in the areas farther away. The authors attributed this combined effect to continuously increasing spillover (Stobart et al. 2009).

The comparison between the analyses for single gears and standardized gears also provided striking insights. The decline of catch rates with distance from the no-take area was more apparent for the analyses of standardized gears, for which we expected an equal or lower effort concentration around the no-take area boundaries. This became particularly obvious in the multiple regression models. In contrast, effects of time were more accentuated for the analyses of single gears, which were expected to benefit most from protection. Effects of both time and distance suggested fisheries benefits owing to the presence of the MPA. The greatest difference was observed in relation to the size of the no-take area. While catch rates of single gears were higher for larger MPAs, the opposite was observed for standardized gears. Meta-analytical studies comparing biological variables of fish communities inside and outside no-take areas found no (Côté et al. 2001; Halpern 2003; Guidetti and Sala 2007) or positive effects (Claudet et al. 2008) for the size of the no-take areas. The mechanisms behind the patterns in our results are difficult to determine. Both theory and modelling focussed on the mobility of different life stages of species to make predictions about the adequate no-take area size (De Martini 1993; Botsford et al. 2003; Hastings and Botsford 2003; Le Quesne and Codling 2009). Within this line of reasoning, Hastings and Botsford (2003) predicted that the fisheries objectives of maximizing yields would be best met with smaller no-take areas, as opposed to the conservation objectives, that would be best served by larger no-take areas. Although our results for the entire fishery in the vicinity of the MPAs corroborated these predictions, our results for single gears suggest that other processes need to be taken into account. Differences in species characteristics are a possible but rather unlikely factor, as both analyses considered a broad range of species with different mobility. We can hypothesize that larger no-take areas, with a larger perimeter, could have a more dispersed fishing effort near their borders, but effort allocation by fishermen is complex and influenced by many factors such as social behaviour and weather conditions (Wilcox and Pomeroy 2003). Determining the processes behind the patterns we observed will require further investigation which is beyond the scope of this study.

An important result of our analysis was the difference between response variables for the marketable catch and the catch of target species. Mean effect sizes were higher and the effects were generally similar or stronger for the marketable catch. This indicates that effects of MPAs on catch rates 
are more easily detectable for the marketable catch. Furthermore, simple regressions demonstrated that the difference becomes greater with time, although this could not be formally tested. Only the regression lines of the marketable catch attained positive values during the period of the study (after approximately 20 years). It is unclear whether this is an indication of a more diverse fish community in the vicinity of the no-take area. Even so, in terms of CPUE, the greatest benefit for the fishermen seems to be realized through the increased by-catch per unit of effort. By the definition of by-catch, this is a real benefit because it represents increased return to the fishermen relative to the effort they invest. Increased income in the vicinity of an MPA has previously been shown to overlap with increased species diversity (Stelzenmüller et al. 2008b).

The present study demonstrates that southern European MPAs have clear effects on the surrounding fisheries: on the catch rate of target species, but especially on the catch rate of the total marketable catch. Moreover, these effects depend on the length of time an area has benefited from protection and on the size of the no-take area. It needs to be emphasized that although the multiple regression models were often significant, they explained between $15 \%$ and $75 \%$ of the total variability, indicating that the heterogeneity in catch rates is also influenced by other factors. These factors could be related to the design (size and regulations of the partial-take area(s), connectivity with other MPAs), physical environment and history (exploitation and poaching history) of the MPAs. While these factors could not be investigated because they could not be satisfactorily quantified or did not show enough variation, the robustness of the present study would also have benefitted from a better spread of the covariates we analysed (i.e. time, size and distance). Compiling such a data set, especially for a single biogeographical region, would be very challenging, especially considering that the present analyses draw upon some of the more available CPUE data for both this region and perhaps internationally, but undoubtedly a worthwhile endeavour. In this context, it is important to highlight that we did not consider any biological information, such as mobility and life-history traits, of the species in our analyses, although these characteristics are likely to influence the observed patterns. For each gear, species were simply categorized as target or by-catch and grouped together for analysis because there was no single species that was sufficiently abundant and similarly commercially important in all MPAs. Despite these limitations and acknowledging that this study is no substitute for properly designed monitoring studies, which can also provide information on mechanisms driving MPA effects, we conclude that our findings provide crucial information for the design, management and evaluation of MPAs as fisheries management tools.

\section{Acknowledgements}

This work has been carried out with financial support from the Commission of the European Community, specific RTD programme "Specific Support to Policies", SSP-2003-006539 “European Marine Protected Areas as Tools for Fisheries Management and Conservation (EMPAFISH)". It does not necessarily reflect its views and in no way anticipates the Commission's future policy in this area. We also thank all the people involved in gathering and making available of the data included in this study.

\section{References}

Abesamis, R.A. and Russ, G.R. (2005) Density-Dependent Spillover From a Marine Reserve: Long-Term Evidence. Ecological Applications 15, 1798-1812.

Botsford, L.W., Micheli, F. and Hastings, A. (2003) Principles for the Design of Marine Reserves. Ecological Applications 13, S25-S31.

Claudet, J., Osenberg, C.W., Benedetti-Cecchi, L. et al. (2008) Marine Reserves: Size and Age Do Matter. Ecology Letters 11, 481-489.

COM (2002) 535 final. Communication from the Commission to the Council and the European Parliament laying down a Community Action Plan for the conservation and sustainable exploitation of fisheries resources in the Mediterranean Sea under the Common Fisheries Policy.

Côté, I.M., Mosqueira, I. and Reynolds, J.D. (2001) Effects of Marine Reserve Characteristics on the Protection of Fish Populations: a Meta-Analysis. Journal of Fish Biology 59, $178-189$.

De Martini, E.E. (1993) Modeling the Potential of Fishery Reserves for Managing Pacific Coral Reef Fishes. Fishery Bulletin 91, 414-427.

Floeter, S.R., Halpern, B.S. and Ferreira, C.E.L. (2006) Effects of fishing and protection on Brazilian reef fishes. Biological Conservation 128, 391-402.

Gell, F.R. and Roberts, C.M. (2003) Benefits Beyond Boundaries: the Fishery Effects of Marine Reserves. Trends in Ecology \& Evolution 18, 448-455. 
Gomez, S., Lloret, J., Demestre, M. and Riera, V. (2006) The decline of the artisanal fisheries in the Mediterranean coastal areas: the case of Cap de Creus (Cape Creus). Coastal Management 34, 217-232.

Goñi, R., Quetglas, A. and Renones, O. (2006) Spillover of Spiny Lobsters Palinurus Elephas From a Marine Reserve to an Adjoining Fishery. Marine Ecology-Progress Series 308, 207-219.

Goñi, R., Adlerstein, S., Alvarez-Berastegui, D. et al. (2008) Spillover from six western Mediterranean marine protected areas: evidence from artisanal fisheries. Marine Ecology-Progress Series 366, 159-174.

Guidetti, P. and Sala, E. (2007) Community-Wide Effects of Marine Reserves in the Mediterranean Sea. Marine Ecology-Progress Series 335, 43-56.

Gurevitch, J. and Hedges, L.V. (1999) Statistical issues in ecological meta-analyses. Ecology 80, 1142-1149.

Halpern, B.S. (2003) The Impact of Marine Reserves: Do Reserves Work and Does Reserve Size Matter? Ecological Applications 13, S117-S137.

Halpern, B.S. and Warner, R.R. (2002) Marine Reserves Have Rapid and Lasting Effects. Ecology Letters 5, 361366.

Halpern, B.S., Gaines, S.D. and Warner, R.R. (2004) Confounding Effects of the Export of Production and the Displacement of Fishing Effort From Marine Reserves. Ecological Applications 14, 1248-1256.

Harmelin, J.G. (2000) Mediterranean Marine Protected Areas: Some Prominent Traits and Promising Trends. Environmental Conservation 27, 104-105.

Hastings, A. and Botsford, L.W. (1999) Equivalence in Yield From Marine Reserves and Traditional Fisheries Management. Science 284, 1537-1538.

Hastings, A. and Botsford, L.W. (2003) Comparing Designs of Marine Reserves for Fisheries and for Biodiversity. Ecological Applications 13, S65-S70.

Hedges, L.V., Gurevitch, J. and Curtis, P.S. (1999) The meta-analysis of response ratios in experimental ecology. Ecology 80, 1150-1156.

Hilborn, R., Stokes, K., Maguire, J.J. et al. (2004) When Can Marine Reserves Improve Fisheries Management? Ocean \& Coastal Management 47, 197-205.

Jaworski, A., Solmundsson, J. and Ragnarsson, S.A. (2006) The Effect of Area Closures on the Demersal Fish Community Off the East Coast of Iceland. ICES Journal of Marine Science 63, 897-911.

Jennings, S. (2001) Patterns and Prediction of population recovery in marine reserves. Reviews in Fish Biology and Fisheries 10, 209-231.

Kaunda-Arara, B. and Rose, G.A. (2004) Effects of marine reef National Parks on fishery CPUE in coastal Kenya. Biological Conservation 118, 1-13.

Kellner, J.B., Tetreault, I., Gaines, S.D. and Nisbet, R.M. (2007) Fishing the Line Near Marine Reserves in Single and Multispecies Fisheries. Ecological Applications 17, 1039-1054.
Le Quesne, W.J.F. and Codling, E.A. (2009) Managing mobile species with MPAs: the effects of mobility, larval dispersal, and fishing mortality on closure size. ICES Journal of Marine Science 66, 122-131.

Maunder, M.N. and Punt, A.E. (2004) Standardizing catch and effort data: a review of recent approaches. Fisheries Research 70, 141-159.

McClanahan, T.R. and Kaunda-Arara, B. (1996) Fishery Recovery in a Coral-Reef Marine Park and Its Effect on the Adjacent Fishery. Conservation Biology 10, 11871199.

McClanahan, T.R. and Mangi, S. (2000) Spillover of Exploitable Fishes From a Marine Park and Its Effect on the Adjacent Fishery. Ecological Applications 10, 17921805.

Micheli, F., Halpern, B.S., Botsford, L.W. and Warner, R.R. (2004) Trajectories and Correlates of Community Change in No-Take Marine Reserves. Ecological Applications 14, 1709-1723.

Molloy, P.P., McLean, I.B. and Côté, I.M. (2009) Effects of marine reserve age on fish populations: a global metaanalysis. Journal of Applied Ecology 46, 743-751.

Mosqueira, I., Côté, I.M., Jennings, S. and Reynolds, J.D. (2000) Conservation Benefits of Marine Reserves for Fish Populations. Animal Conservation 3, 321-332.

Murawski, S.A., Rago, P.J. and Fogarty, M.J. (2004). Spillover Effects from Temperate Marine Protected Areas. in: Aquatic Protected Areas as Fisheries Management Tools (Proceedings of the American Fisheries Society Symposium 42, Quebec, 11-12 August, 2003) (ed. J.B. Shipley). American Fisheries Society, Bethesda, pp. 167184.

Murawski, S.A., Wigley, S.E., Fogarty, M.J., Rago, P.J. and Mountain, D.G. (2005) Effort Distribution and Catch Patterns Adjacent to Temperate MPAs. ICES Journal of Marine Science 62, 1150-1167.

Nowlis, J.S. and Roberts, C.M. (1999) Fisheries Benefits and Optimal Design of Marine Reserves. Fishery Bulletin 97, 604-616.

Piet, G.J. and Rijnsdorp, A.D. (1998) Changes in the Demersal Fish Assemblage in the South-Eastern North Sea Following the Establishment of a Protected Area ("Plaice Box"). ICES Journal of Marine Science 55, 420429.

Planes, S., Garcia-Charton, J.A., Marcos, C. and PerezRuzafa, A. (Coord.) (2008). Ecological effects of AtlantoMediterranean marine protected areas in the European Union. EMPAFISH project, Booklet n1. Editum. 158pp. Available at http://www.um.es/empafish. (Accessed 10/11/2010).

Roberts, C.M., Bohnsack, J.A., Gell, F., Hawkins, J.P. and Goodridge, R. (2001) Effects of Marine Reserves on Adjacent Fisheries. Science 294, 1920-1923.

Rodwell, L.D., Barbier, E.B., Roberts, C.M. and Mcclanahan, T.R. (2002) A Model of Tropical Marine Reserve- 
Fishery Linkages. Natural Resource Modelling 15, 453486.

Rodwell, L.D., Barbier, E.B., Roberts, C.M. and Mcclanahan, T.R. (2003) The Importance of Habitat Quality for Marine Reserve Fishery Linkages. Canadian Journal of Fisheries and Aquatic Sciences 60, 171-181.

Rosenberg, M.S., Adams, D.C. and Gurevitch, J. (2000) MetaWin: Statistical software for meta-analysis (vers. 2.0). Sunderland, MA: Sinauer Associates, Inc.

Russ, G.R. (2002) Marine Reserves as Reef Fisheries Management Tools: Yet Another Review. In: Coral Reef Fishes, Dynamics and diversity in a complex ecosystem (ed. P.F. Sale). Academic Press, San Diego, California, USA, pp. $421-443$.

Russ, G.R. and Alcala, A.C. (1996) Marine Reserves: Rates and Patterns of Recovery and Decline of Large Predatory Fish. Ecological Applications 6, 947-961.

Russ, G.R. and Alcala, A.C. (1998) Natural Fishing Experiments in Marine Reserves 1983 - 1993: Roles of Life History and Fishing Intensity in Family Responses. Coral Reefs 17, 399-416.

Russ, G.R. and Alcala, A.C. (2004) Marine reserves: longterm protection is required for full recovery of predatory fish populations. Oecologia 138, 622-627.

Russ, G.R., Stockwell, B. and Alcala, A.C. (2005) Inferring Versus Measuring Rates of Recovery in No-Take Marine Reserves. Marine Ecology-Progress Series 292, 1-12.

Sale, P.F., Cowen, R.K., Danilowicz, B.S. et al. (2005) Critical Science Gaps Impede Use of No-Take Fishery Reserves. Trends in Ecology \& Evolution 20, 74-80.

Samoilys, M.A., Martin-Smith, K.M., Giles, B.G. et al. (2007) Effectiveness of Five Small Philippines' Coral Reef Reserves for Fish Populations Depends on SiteSpecific Factors, Particularly Enforcement History. Biological Conservation 136, 584-601.
Stelzenmüller, V., Maynou, F. and Martin, P. (2007) Spatial Assessment of Benefits of a Coastal Mediterranean Marine Protected Area. Biological Conservation 136, 571-583.

Stelzenmüller, V., Maynou, F., Bernard, G. et al. (2008a) Spatial assessment of fishing effort around European marine reserves: implications for successful fisheries management. Marine Pollution Bulletin 56, 2018-2026.

Stelzenmüller, V., Maynou, F. and Martin, P. (2008b) Patterns of species and functional diversity around a coastal marine reserve: a fisheries perspective. Aquatic Conservation: Marine and Freshwater Ecosystems $\mathbf{1 8}$ $1-12$.

Stobart, B., Warwick, R., González, C. et al. (2009) Longterm and spillover effects of a marine protected area on an exploited fish community. Marine Ecology-Progress Series 384, 47-60.

Vandeperre, F., Higgins, R., Santos, R.S., Marcos, C. and Perez-Ruzafa, A. (Coord.) (2008) Fishery regimes in Atlanto-Mediterranean European marine protected areas. EMPAFISH project, Booklet n2. Editum. 108pp. Available at http://www.um.es/empafish. (Accessed 10/ 11/2010).

Wilcox, C. and Pomeroy, C. (2003) Do commercial fishers aggregate around marine reserves? Evidence from Big Creek Marine Ecological Reserve, central California. North American Journal of Fisheries Management 23, 241250.

Willis, T.J., Millar, R.B., Babcock, R.C. and Tolimieri, N. (2003) Burdens of Evidence and the Benefits of Marine Reserves: Putting Descartes Before Des Horse? Environmental Conservation 30, 97-103.

Zeller, D. and Reinert, J. (2004) Modelling Spatial Closures and Fishing Effort Restrictions in the Faroe Islands Marine Ecosystem. Ecological Modelling 172, 403-420. 